\title{
Maternal hepatitis B virus carrier status and pregnancy outcomes: a prospective cohort study
}

Ai-Ming Cui ${ }^{1 \dagger}$, Xiao-Yan Cheng ${ }^{1 \dagger}$, Jian-Guo Shao ${ }^{2 \dagger}$, Hai-Bo Li $^{3}$, Xu-Lin Wang $^{4}$, Yi Shen ${ }^{4}$, Li-Jing Mao ${ }^{1}$, Sheng Zhang ${ }^{4}$, Hai-Yun Liu', Lei Zhang ${ }^{5}$ and Gang Qin ${ }^{2,4^{*}}$

\begin{abstract}
Background: Infection with hepatitis B virus (HBV) in pregnant women may be a threat for both mothers and fetuses. This study was performed to explore the impact of maternal HBV carrier status on pregnancy outcomes.

Methods: We conducted a prospective cohort study at the Obstetrics \& Gynecology Hospital of Nantong University between January 1, 2012 and September 30, 2015. A consecutive sample of 21,004 pregnant women, 513

asymptomatic HBV carriers and 20,491 non-HBV controls, was included in this study. The main outcomes of interest were selected pregnancy outcomes including miscarriage, stillbirth, preterm birth (PTB), gestational diabetes (GDM), intrahepatic cholestasis of pregnancy (ICP), preterm premature rupture of the membrane (PPROM), low birth weight (LBW), small for gestational age (SGA) and Apgar scores. The incidence of adverse pregnancy outcomes between asymptomatic HBV carriers and non-HBV controls were compared using the chi-square test and logistic regression. $P$ values were two sided, and $P<0.05$ was considered to indicate statistical significance.

Results: The incidences of stillbirth, PTB, GDM, ICP, PPROM, LBW, and SGA were similar between the HBV carrier and non-HBV groups. The proportion of miscarriage was significantly higher among the HBV carriers than the controls ( $9.36 \%$ vs $5.70 \%$; $P<0.001)$. After using multivariate modelling to adjust for possible socio-demographical variables and obstetric complications, women with HBV carrier status were still more likely to have miscarriage (adjusted OR 1.71, $95 \% \mathrm{Cl}$ 1.23-2.38). In addition, the incidences of other maternal and neonatal outcomes were similar between the two groups.
\end{abstract}

Conclusion: Maternal HBV carrier status may be an independent risk factor for miscarriage and careful surveillance is warranted.

Keywords: Pregnancy, Hepatitis B virus infection, Miscarriage

\section{Background}

Hepatitis B virus (HBV) infection is one of the most common health problems worldwide. The prevalence of HBV infection among women of childbearing age may be as high as $2-8 \%$ in China $[1,2]$, whereas in the USA it is only $0.4 \%$ [3]. Most pregnant women with $\mathrm{HBV}$ infection are chronic carriers, indicated by positive

\footnotetext{
* Correspondence: tonygqin@ntu.edu.cn

${ }^{\dagger}$ Equal contributors

${ }^{2}$ Center for Liver Diseases, Nantong Third People's Hospital, Nantong

University, Nantong, Jiangsu, China

${ }^{4}$ Department of Epidemiology and Medical Statistics, School of Public Health, Nantong University, 9 Se-Yuan Road, Nantong, Jiangsu 226000, China Full list of author information is available at the end of the article
}

serum hepatitis B surface antigen (HBsAg) status. HBsAg expression has also been found in cells of the ovarian follicle or placental capillary endothelium [4]. Intrauterine infection and vertical transmission of $\mathrm{HBV}$ is a fundamental reason why there are so many chronic HBV carriers in China. The overall estimated rates of immunoprophylaxis failure for infants with $\mathrm{HBsAg}$ positive and HBeAg-positive mothers were 4.87 and $9.66 \%$ respectively [5].

Although HBV carrier status is relatively common among pregnant women, especially in highly endemic countries such as China, there is a paucity of data regarding the impact of maternal HBV infection on the 
risk for adverse pregnancy outcomes. The limited studies on this issue have always yielded conflicting results [6-15].

Due to this dearth of information, we undertook this hospital-based prospective cohort study, which seeks to examine the association of HBV carrier status with pregnancy outcomes.

\section{Methods}

\section{Study design and participant population}

We conducted a prospective cohort study at the Obstetrics \& Gynecology Hospital of Nantong University, China between January 1, 2012 and September 30, 2015. All pregnant women who visited the tertiary teaching hospital were screened and recruited through 2012 to 2014. Data on maternal characteristics (age, education, medical history) were taken from questionnaires completed by women after their first antenatal visit. Body mass index (BMI) was classified according to the WHO classification: underweight $\left(<18.5 \mathrm{~kg} / \mathrm{m}^{2}\right)$, normal weight $\left(18.5-24.9 \mathrm{~kg} / \mathrm{m}^{2}\right)$, overweight $\left(25-29.9 \mathrm{~kg} / \mathrm{m}^{2}\right)$ or obesity $\left(\geq 30 \mathrm{~kg} / \mathrm{m}^{2}\right)$ [16]. As part of standard prenatal care at our hospital, all women are screened in the first trimester of pregnancy for hepatitis B surface antigen (HBsAg), hepatitis $\mathrm{B}$ e antigen ( $\mathrm{HBeAg}$ ), IgG antibodies against HCV and HIV, syphilis tests with the treponema pallidum particle agglutination assay (TP-PA) and RPR, specific IgM antibodies against toxoplasma, rubella virus, CMV and HSV-1/2.

All enrolled participants fulfilled the following criteria: (i) normal alanine transaminase (ALT) at study entry; (ii) no evidence of hepatitis $\mathrm{C}$ virus (HCV) infection (antiHCV negative), (iii) absence of human immunodeficiency virus (HIV) infection (anti-HIV negative) and active syphilis infection (rapid plasma reagin test/RPR negative); (iv) absence of IgM antibodies against toxoplasma (TOX), rubella virus (RV), cytomegalovirus (CMV), herpes simplex virus (HSV-1/2); (v) exclusion of other liver diseases such as alcoholic liver diseases (ALDs), nonalcoholic fatty liver diseases (NAFLDs) or autoimmune liver diseases (AILDs); (vi) absence of preexisting chronic diseases such as diabetes mellitus, hypertension, or heart diseases. HBV carriers were defined as: HBsAg positivity $>6$ months confirmed by previous medical history, and persistently normal levels of ALT before and at study entry. In addition, HBV carriers were excluded if they had received antiviral treatment within the previous year.

A total of 24,713 pregnant women were reviewed and screened in their first trimester of pregnancy at the Obstetrics \& Gynecology Hospital of Nantong University, China. Of these, 3382 were excluded: due to abnormal ALT or other liver diseases (HCV infection, ALDs, NAFLDs, or AILDs) in 1065 subjects; due to other infection (HIV infection, active syphilis infection, positivity of
anti-TOX IgM, anti-RV IgM, anti-CMV IgM or antiHSV IgM) in 1788 subjects; due to concurrent medical complications (DM, hypertension or heart diseases) in 529 subjects. Thereafter, 21,331 pregnant women were enrolled in this study, including 519 asymptomatic HBV carriers and 20,812 non-HBV controls. Most of the enrolled subjects received at least three health examinations and were followed-up until delivery or miscarriage. 327 subjects were excluded because of the following reasons: acute hepatitis in 35 subjects (hepatitis E in 27 subjects and hepatitis A in eight subjects); lost to followup in 159 subjects; incomplete data in 133 subjects. Finally, 21,004 subjects, with 513 asymptomatic HBV carriers (HBeAg positive in 159 subjects) and 20,491 non-HBV controls, were included to evaluate the effect of chronic HBV carrier status on the pregnancy outcomes (Fig. 1).

The study protocol was approved by the institutional ethics committee of the Obstetrics \& Gynecology Hospital of Nantong University and conducted in accord with the guidelines of the Declaration of Helsinki. Written informed consent was obtained from each patient.

\section{Pregnancy outcomes}

Primary pregnancy outcomes were: miscarriage (spontaneous abortion), preterm $(<37 \mathrm{w})$, or stillbirth (after 20 completed gestational weeks). Other maternal outcomes included preeclampsia, gestational diabetes (GDM), placenta previa, placental abruption, and preterm premature rupture of the membranes (PPROM). Neonatal outcomes for singleton pregnancy included low birth weight (LBW, $<2,500 \mathrm{~g})$ or macrosomia $(\geq 4,000 \mathrm{~g})$, small for gestational age (SGA; defined as a birth weight below the 10th percentile for each gestational age using sex-specific criteria) $[17,18]$ and Apgar score $(<7$ at $5 \mathrm{~min}$ ). The rate of cesarean section was not assessed because China has nearly $50 \%$ caesarean delivery rate due to "social influence" rather than medical or obstetric indication [19].

\section{Statistical analysis}

According to a recent survey conducted in China, the prevalence of HBsAg among pregnant women was $6.1 \%$ [1]. With the assumption that the ratio of HBV carriers to non-HBV subjects was 1:20, the baseline risk for adverse pregnancy outcome was $5 \%$ and there might be 2 -fold increase of risk with a power of $80 \%$, the minimum sample size of approximately 4200 participants including $200 \mathrm{HBV}$ carriers were required.

The continuous data were expressed as mean \pm standard deviation (SD) and categorical data as number or percent. Comparison of continuous variables was done by student $t$ test. For categorical variables the chi-square or Fisher's exact test were used. Selected maternal and neonatal 


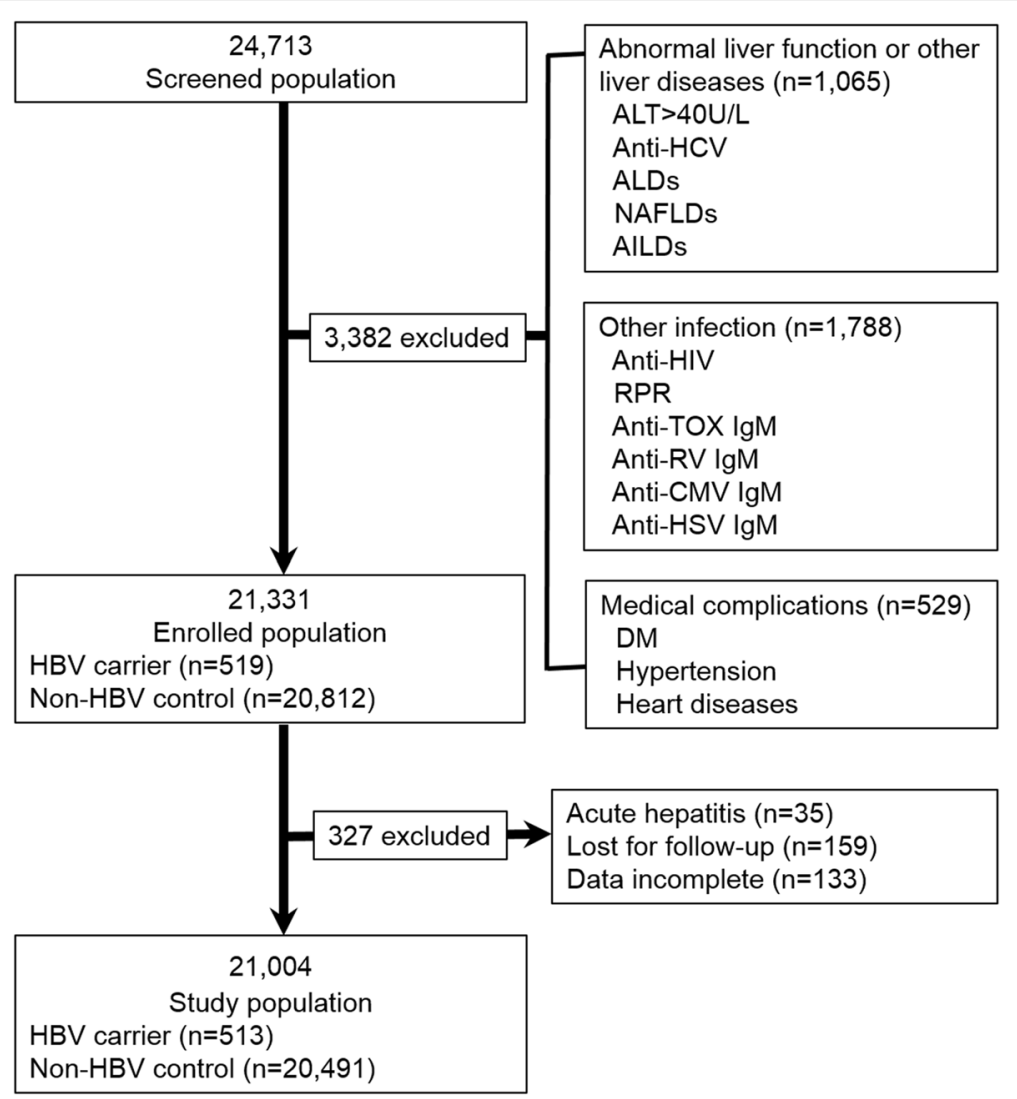

Fig. 1 Flow chart for study population. HBV, hepatitis B virus; ALT, alanine transaminase; HCV, hepatitis C virus; HIV human immunodeficiency virus; RPR, rapid plasma reagin test; TOX, toxoplasma; RV, rubella virus; CMV, cytomegalovirus, HSV, herpes simplex virus; ALD, alcoholic liver disease; NAFLD, nonalcoholic fatty liver diseases; AILD, autoimmune liver disease; DM, diabetes mellitus

outcomes in all pregnancies or singleton pregnancies were calculated per woman and/or per infant when appropriate. In this analysis, miscarriage was taken as the dependent variable. Demographic, education, medical history, and laboratory factors were taken as independent variables. Risk factors found significant on univariate analysis were entered into multivariate logistic regression model. All statistical tests were 2-tailed, and a significance level $(P)$ of 0.05 was used. The statistical analyses were performed with Stata version 13 (StataCorp, USA).

\section{Results}

\section{Participant characteristics}

The demographic and clinical data of 21,004 study subjects are shown in Table 1. The mean age (SD) of the asymptomatic HBV carrier group was slightly but significantly older than that of the control group $(27.59 \pm 4.02$ vs. $27.03 \pm 4.19$ years, $P<0.01)$. But no significant difference was found between the two groups in terms of the proportion of older pregnant women (aged 35 years or more). HBV carriers also had significantly higher serum ALT levels than controls (24.75 \pm 7.22 vs.
$22.34 \pm 6.49 \mathrm{U} / \mathrm{L}, P<0.001)$. Moreover, there was no significant difference in terms of height, pre-maternal BMI, education level, parity, history of miscarriage or preterm birth, plurality, and in vitro fertilization (IVF) between the HBV carriers and the controls.

During the follow-up, 20885 patients had persistently normal levels of serum ALT, while 119 (0.57 \%) patients experienced at least one episode of ALT > the upper limit of normal (ULN, 40U/L). Among them, $6 \mathrm{HBV}$ carriers and 112 non-HBV controls showed a mild ALT increase $(\leq 2 \mathrm{ULN})$, while only 1 non-HBV subject showed a moderate ALT increase ( $>2 \mathrm{ULN})$. All the ALT elevation was transient and usually recovered to normal levels within 3 months.

\section{Pregnancy outcomes}

The mean (SD) of completed weeks' gestation was significantly shorter in HBV carriers than in the non-HBV controls $(35.79 \pm 8.29$ vs. $36.95 \pm 6.76 ; P<0.001)$. The proportion of miscarriage was significantly higher among the HBV carriers than the controls $(9.36 \%$ vs $5.70 \%$; $P<0.001)$. Meanwhile, there was no significant difference between the two groups for most of the pregnancy 
Table 1 Baseline characteristics of the study population ${ }^{\text {a }}$

\begin{tabular}{|c|c|c|c|}
\hline Characteristic & HBV carriers $(n=513)$ & Controls $(n=20491)$ & $P$ \\
\hline Maternal age (y) & $27.59 \pm 4.02$ & $27.03 \pm 4.19$ & 0.003 \\
\hline$\leq 19$ & 2 & 239 & 0.234 \\
\hline $20-34$ & 476 & 18,974 & \\
\hline$\geq 35$ (older pregnancy) & 35 & 12,78 & \\
\hline Height (cm) & $156.23 \pm 8.43$ & $155.81 \pm 7.32$ & 0.201 \\
\hline Pre-pregnancy BMI & $22.34 \pm 5.86$ & $22.02 \pm 5.69$ & 0.209 \\
\hline$<18.5$ & 35 & 1,751 & 0.396 \\
\hline $18.5-24.9$ & 408 & 16,137 & \\
\hline $25-29.9$ & 67 & 2,536 & \\
\hline$\geq 30$ & 3 & 67 & \\
\hline \multicolumn{4}{|l|}{ Education } \\
\hline Primary/under & 15 & 892 & 0.288 \\
\hline Middle/High school & 171 & 6,785 & \\
\hline College/above & 327 & 12,814 & \\
\hline \multicolumn{4}{|l|}{ Parity } \\
\hline 0 & 373 & 15,524 & 0.258 \\
\hline 1 & 126 & 4,519 & \\
\hline$\geq 2$ & 14 & 448 & \\
\hline \multicolumn{4}{|l|}{ Previous abortion } \\
\hline 0 & 456 & 18,607 & 0.385 \\
\hline 1 & 42 & 1,329 & \\
\hline$\geq 2$ & 15 & 555 & \\
\hline Previous preterm birth & & & 0.907 \\
\hline 0 & 504 & 20,168 & \\
\hline 1 & 9 & 320 & \\
\hline$\geq 2$ & 0 & 3 & \\
\hline \multicolumn{4}{|l|}{ Plurality } \\
\hline 1 & 497 & 20,001 & 0.288 \\
\hline$\geq 2$ & 16 & 490 & \\
\hline \multicolumn{4}{|l|}{ IVF } \\
\hline No & 509 & 20,344 & 0.869 \\
\hline Yes & 4 & 147 & \\
\hline $\mathrm{ALT}(\mathrm{U} / \mathrm{L})$ & $24.75 \pm 7.22$ & $22.34 \pm 6.49$ & $<0.001$ \\
\hline
\end{tabular}

Abbreviations: $B M I$ body mass index, IVF in vitro fertilization

${ }^{a}$ Values are reported as mean $\pm S D$, compared with $t$ test, or number, compared with $x^{2}$ test, unless otherwise indicated

outcomes such as preterm birth, stillbirth, GDM, ICP, placenta previa or PPROM (Table 2).

In singleton pregnancy, the rate of miscarriage was also significantly higher in HBV carrier group than in the control group ( $9.66 \%$ vs. $5.81 \%, P<0.001)$. Preterm birth occurred in 36/497 (7.24 \%) and 1462/20,001 (7.31 \%) of pregnancies in HBV carrier and control group respectively $(P>0.05)$. The mean $(\mathrm{SD})$ birth weight was 3311.26 (510.34) $\mathrm{g}$ and 3330 (509.08) $\mathrm{g}$ in the two groups respectively $(P>0.05)$. Comparable neonatal adverse outcomes occurred in the two groups (e.g., <1,500 g: $0.80 \%$ vs. $0.54 \%$; $<2,500$ g: $5.03 \%$ vs. $4.52 \%$; SGA: $4.43 \%$ vs. $5.16 \%$; respectively). There were no significant differences in incidences of perinatal mortality or Apgar score $<7$ at 5 min (Table 3).

\section{Risk factors associated with miscarriage}

Table 4 presents crude and adjusted odds ratios (ORs) and $95 \%$ confidence intervals (CIs) of miscarriage associated with demographic, physical, reproductive and laboratory characteristics. When single factors were analyzed for the risk of miscarriage, five factors had been 
Table 2 Comparison of the pregnancy outcomes between asymptomatic HBV carriers and non-HBV controls ${ }^{a}$

\begin{tabular}{|c|c|c|c|}
\hline Outcome & HBV carriers $(n=513)$ & Controls $(n=20,491)$ & $P$ \\
\hline Completed weeks' gestation & $35.79 \pm 8.29$ & $36.95 \pm 6.76$ & $<0.001$ \\
\hline$\leq 12 \mathrm{wks}$ & 36 & 822 & 0.002 \\
\hline $121 / 7$ to 28 wks & 13 & 390 & \\
\hline $281 / 7$ to 40 wks & 369 & 14,755 & \\
\hline$>40$ wks & 95 & 4,524 & \\
\hline Preterm birth & 49 (9.55\%) & $1,718(8.38 \%)$ & 0.347 \\
\hline Stillbirth & 0 & 18 (0.09\%) & 0.502 \\
\hline Miscarriage & $48(9.36 \%)$ & $1,167(5.70 \%)$ & $<0.001$ \\
\hline Preeclampsia & $4(0.78 \%)$ & $216(1.05 \%)$ & 0.600 \\
\hline GDM & $6(1.17 \%)$ & $232(1.13 \%)$ & 0.937 \\
\hline ICP & $12(2.34 \%)$ & $331(1.62 \%)$ & 0.201 \\
\hline Placenta previa & $4(0.78 \%)$ & $216(1.05 \%)$ & 0.547 \\
\hline PPROM & $23(4.48 \%)$ & $845(4.12 \%)$ & 0.686 \\
\hline
\end{tabular}

Abbreviations: GDM Gestational diabetes, ICP intrahepatic cholestasis of pregnancy, PPROM preterm premature rupture of the membrane

avalues are reported as mean $\pm S D$, compared with $t$ test, or number (percentage), compared with $\chi^{2}$ test, unless otherwise indicated

identified: (i) history of miscarriage with crude OR of 7.95 (95 \% CI 6.85-9.22) for once and crude OR of 18.89 (95 \% CI 15.72-22.71) for twice or more respectively; (ii) in vitro fertilization (crude OR 2.37, 95 \% CI 1.46-3.84); (iii) older age (crude OR 2.22, 95 \% CI 1.85-2.66); (iv) HBV carrier status (crude OR 1.71, $95 \%$ CI 1.26-2.31); and (v) nulliparity (crude OR 1.48, 95 \% CI 1.31-1.69). We did not find the association of education level, pre-maternal BMI with miscarriage risk. Furthermore, we examined the covariates associated with miscarriage using multivariable logistic

Table 3 Neonatal outcomes in singleton pregnancy ${ }^{a}$

\begin{tabular}{|c|c|c|c|}
\hline Outcome & HBV carriers $(n=497)$ & Controls $(n=20,001)$ & $P$ \\
\hline Full-term birth & $413(83.10 \%)$ & $17,364(86.82 \%)$ & 0.016 \\
\hline Preterm birth & $36(7.24 \%)$ & 1462 (7.31 \%) & 0.955 \\
\hline Stillbirth & 0 & 12 (0.06 \%) & 0.585 \\
\hline Miscarriage & $48(9.66 \%)$ & 1163 (5.81 \%) & $<0.001$ \\
\hline Weight of neonates (g) & $3311.26 \pm 510.34$ & $3330 \pm 509.08$ & 0.436 \\
\hline Unknown & 0 & 9 & \\
\hline$<1500 \mathrm{~g}$ & 4 & 108 & 0.585 \\
\hline $1500-2500 \mathrm{~g}$ & 21 & 797 & \\
\hline 2500-3999 g & 392 & 17,489 & \\
\hline$\geq 4000 \mathrm{~g}$ & 32 & 1,598 & \\
\hline \multicolumn{4}{|l|}{ LBW } \\
\hline Unknown & 0 & 9 & \\
\hline No & 472 & 19,087 & 0.594 \\
\hline Yes & 25 & 905 & \\
\hline \multicolumn{4}{|l|}{ SGA $<10$ centile } \\
\hline Unknown & 0 & 9 & 0.461 \\
\hline No & 475 & 18,959 & \\
\hline Yes & 22 & 1,033 & \\
\hline Apgar at $5 \mathrm{~min}$ & $9.90 \pm 0.53$ & $9.87 \pm 0.69$ & 0.336 \\
\hline$\geq 7$ & 488 & 19,744 & 0.292 \\
\hline$<7$ & 9 & 257 & \\
\hline
\end{tabular}


Table 4 Risk factors associated with miscarriage

\begin{tabular}{|c|c|c|c|}
\hline & Cases/Exposed & Crude OR (95\% Cl) & Adjusted OR (95\% Cl) \\
\hline \multicolumn{4}{|l|}{ Age } \\
\hline$<35$ & 1067/19691 & 1 & 1 \\
\hline$\geq 35$ & $148 / 1313$ & $2.22(1.85-2.66)$ & $1.17(0.94-1.45)$ \\
\hline \multicolumn{4}{|l|}{ Nulliparity } \\
\hline No & $830 / 15897$ & 1 & 1 \\
\hline Yes & $385 / 5107$ & $1.48(1.31-1.69)$ & $1.80(1.54-2.11)$ \\
\hline \multicolumn{4}{|l|}{ Education } \\
\hline High school/under & $497 / 8063$ & 1 & \\
\hline College/above & $718 / 12941$ & $0.83(0.67-1.19)$ & \\
\hline \multicolumn{4}{|l|}{ Pre-maternal BMI } \\
\hline$<25$ & 1049/18331 & 1 & \\
\hline$\geq 25$ & $166 / 2673$ & $1.09(0.97-1.42)$ & \\
\hline \multicolumn{4}{|l|}{ Previous abortion } \\
\hline 0 & $673 / 19063$ & 1 & 1 \\
\hline 1 & $309 / 1371$ & $7.95(6.85-9.22)$ & $9.33(7.97-10.92)$ \\
\hline$\geq 2$ & $233 / 570$ & 18.89 (15.72-22.71) & $23.36(19.10-28.57)$ \\
\hline \multicolumn{4}{|l|}{ HBV carrier } \\
\hline No & $1167 / 20491$ & 1 & 1 \\
\hline Yes & $48 / 513$ & $1.71(1.26-2.31)$ & $1.71(1.23-2.38)$ \\
\hline \multicolumn{4}{|l|}{ IVF } \\
\hline No & $1196 / 20853$ & 1 & 1 \\
\hline Yes & $19 / 151$ & $2.37(1.46-3.84)$ & $1.78(1.03-3.05)$ \\
\hline
\end{tabular}

Abbreviations: $B M I$ body mass index, IVF in vitro fertilization

regression. Factors independently associated with miscarriage were: prior abortion (adjusted OR 9.33 for once, adjusted OR 23.36 for twice or more), nulliparity (adjusted OR 1.80), IVF (adjusted OR 1.78), and HBV carrier status (adjusted OR 1.71).

\section{Discussion}

Our prospective cohort study shows that the incidence of miscarriage in pregnant women with chronic HBV infection is significantly higher than that in non-HBV controls. The association remain unchanged after adjustment for other possible maternal confounders such as age, parity and history of abortion. This result is surprising. We for the first time report that HBV carrier status entails a considerable increased risk of miscarriage.

The relationship between viral infections and miscarriage has not been well-understood. On the one hand, several viruses such as CMV, HSV-1/2, human parvovirus B19 (HPV B19), adenovirus, Coxsackie B virus, have been indicated to be causative agents of miscarriage $[20,21]$. On the other hand, the causal relationship of other viruses with miscarriage has not been established for some reasons. First, viral infection of the pregnant women may not always represent fetal infection because of the placental barrier. Second, placental viral infection indicates risk of vertical transmission, but not always transmission to, or disease of the fetus. Last, the intrauterine viral infection does not always cause morbidity or mortality at the early stage of the fetus. For example, the rate of miscarriage following acute varicella did not exceed the rate of miscarriage in pregnant women without chickenpox [22].

The question whether HBV infection in the mothers entails an increased risk for adverse pregnancy outcomes was raised in the 1960s [23], and has been followed by several studies with contradictory and confusing results. For the case-control studies [8-10], the selection bias is a big concern. For the retrospective cohort studies $[11,13-15]$, information for early pregnancy is incomplete. For the prospective cohort studies [7, 12], small sample sizes (with 1576 and 1826 participants respectively) are their major limitation. To the best of our knowledge, this is the first prospective single-center study on HBV carriers during pregnancy to date. Our finding implies that chronic HBV carrier status is likely to affect placental function rather than preterm labor.

The study population had a high level of homogeneity in that nearly all participants were ethnic Han from an 
eastern region of China and all were asymptomatic. Although the prevalence of HBsAg (2.5\%) among pregnant women in this study was much lower than that (6.1\%) in another survey conducted in a southwest region of China in 2010 [1], its epidemiologic power is still strong. In such a sample of more than 500 women who were exposed to chronic HBV infection in pregnancy with a ratio of $1: 40$ to the controls and the assumption of a baseline miscarriage risk of $5 \%$, the detection of a 1.7-fold increase in the rate of miscarriage (with $95 \% \mathrm{CI}$ ), yielded a power of $90 \%$.

It should be noted that in this study asymptomatic HBV carriers had significantly higher serum ALT levels than non-HBV controls, suggesting that even in clinically asymptomatic infection, HBV may still produce adverse effects on the liver. Their longer-term effects on the liver as well as metabolic profiles await further examinations. Asymptomatic HBV carriers can be categorized into two clinical HBV phases: immune tolerance (IT) and inactive carrier (IC) [24]. IT patients had positive serum $\mathrm{HBeAg}$ and repetitive normal ALT values $(<40 \mathrm{IU} / \mathrm{L})$ for at least 1 year. Patients with typical IT form (very high viral load HBV-DNA $\geq 2 \times 10^{6} \mathrm{IU} / \mathrm{mL}$ ) have very limited liver injury, while patients with atypical form (HBV-DNA $<2 \times 10^{6} \mathrm{IU} / \mathrm{mL}$ ) have a potential risk of more severe histological lesions. IC patients had repetitive normal ALT values $(<40 \mathrm{IU} / \mathrm{L})$ for at least 1 year, negative $\mathrm{HBeAg}$ and positive HBeAb. Patients with typical IC form have low viral load (HBV-DNA $<2,000 \mathrm{IU} / \mathrm{mL}$ ) and minimal histological lesions, while patients with atypical form had higher HBV-DNA $(\geq 2,000 \mathrm{IU} / \mathrm{mL})$ remain problematic. Therefore, the absence of symptoms is not enough to accurately separate patients with significant progressive liver injury from inactive HBsAg carriers [25].

Our study has shown that the majority of pregnant women maintain persistently normal levels of serum ALT through the pregnancy. Elevation of ALT was usually within $1-2 \times \mathrm{ULN}$, and decrease to normal levels within three months. The incidence of abnormal ALT is $0.57 \%$ through the study. This rate seems significantly lower than the estimated incidence rate of $3 \%$ for abnormal liver functions as previously reported in other population studies [26]. A possible explanation may be the inclusion criteria of this study, i.e. no pre-existing chronic liver diseases, no concurrent medical diseases, treatment-naive HBV carrier status, and normal ALT level at study entry.

The outcome of a woman's previous pregnancy has profound consequences for her subsequent pregnancies. We found that the most important predictive factor for miscarriage is a history of spontaneous or induced abortion, in accordance with previous studies [27, 28]. The etiology of recurrent pregnancy loss is still unclear
[29]. While induced abortion may increase the risks for both a subsequent preterm delivery and mood disorders substantial, the association of previous induced abortion with subsequent miscarriage remains controversial [30].

Admittedly, our study has several limitations. First of all, we were only able to locate very few data regarding viral load in these HBV carriers. Thus, we were unable to conclude any significant correlation between higher viral loads at the time of pregnancy and adverse outcomes. Second, some potential confounders which might affect pregnancy outcomes have not been included. For example, cigarette, alcohol, and caffeine consumption may be risk factors for miscarriage. Actually, in Chinese culture, women are discouraged from drinking alcohol and from smoking cigarette. Most people drink tea over coffee in China as well. Another limitation is singlecenter nature of this study. Indeed, the Obstetrics \& Gynecology Hospital of Nantong University is the sole special hospital for the treatment of women illnesses in Nantong city, eastern China, and serves more than half of obstetric population in this region.

\section{Conclusion}

This study reflects the clinical reality of pregnant women and indicates that HBV carrier status confers a substantial increased risk for miscarriage. Careful surveillance as high-risk pregnancy is warranted. Further studies are needed to assess the importance of factors such as disease activity, viral characteristics, and other clinical features of the disease.

\section{Ethics}

The study protocol was approved by the institutional ethics committee of the Obstetrics \& Gynecology Hospital of Nantong University and conducted in accord with the guidelines of the Declaration of Helsinki. Written informed consent was obtained from each patient.

\section{Availability of data and materials}

The datasets supporting the conclusions of this article is included within the manuscript.

\footnotetext{
Abbreviations

AlLD: autoimmune liver disease; ALD: alcoholic liver disease; ALT: alanine transaminase; BMI: body mass index; Cl: confidence interval; CMV: cytomegalovirus; DM: diabetes mellitus; GDM: gestational diabetes; HBeAg: hepatitis B e antigen; HBsAg: hepatitis B surface antigen; HBV: Chronic hepatitis B virus; HCV: hepatitis C virus; HIV: human immunodeficiency virus; HPV: human parvovirus; HSV: herpes simplex virus; IVF: in vitro fertilization; LBW: low birth weight; NAFLD: nonalcoholic fatty liver diseases; OR: odds ratio; PPROM: preterm premature rupture of the membranes; RPR: rapid plasma reagin test; RV: rubella virus; SD: standard deviation; SGA: small for gestational age; TOX: toxoplasma; ULN: upper limit of normal; VZV: varicella-zoster virus.
}

Competing interests

The authors declare that they have no competing interests. 


\section{Authors' contributions}

A-MC, X-YC, J-GS, H-BL, L-JM and H-YL carried out the field study. X-LW, YS and SZ performed the statistical analysis. GQ and X-YC drafted the manuscript. GQ, A-MC and J-GS participated in the study design and coordination and helped to refine the manuscript. J-GS, X-LW, L-JM, SZ and H-YL participated in the field investigation. LZ provided valuable discussion and support. All authors read and approved the final manuscript.

\section{Acknowledgements}

The authors would like to thank all participating women.

\section{Funding}

This study was supported in part by grants from the Department of Science and Technology, Jiangsu Province, China (no. BE2015655), the Natural Science Foundation of China (no. 81370520), the Natural Science Foundation of Jiangsu Province, China (no. BK2012653), and the Department of Health, Jiangsu Province, China (no. Q201208).

\section{Author details}

'Department of Obstetrics, The Obstetrics \& Gynecology Hospital of Nantong University, Nantong, Jiangsu, China. ${ }^{2}$ Center for Liver Diseases, Nantong Third People's Hospital, Nantong University, Nantong, Jiangsu, China. ${ }^{3}$ Department of Clinical Laboratory, The Obstetrics \& Gynecology Hospital of Nantong University, Nantong, Jiangsu, China. ${ }^{4}$ Department of Epidemiology and Medical Statistics, School of Public Health, Nantong University, 9 Se-Yuan Road, Nantong, Jiangsu 226000, China. ${ }^{5}$ Faculty of Medicine, Nursing and Health Science, Monash University, Melbourne, VIC, Australia.

Received: 25 November 2015 Accepted: 21 April 2016 Published online: 26 April 2016

\section{References}

1. Huang Y, Li L, Sun X, Lu M, Liu H, Tang G, Wang D, Hutin YJ. Screening of pregnant women for hepatitis $B$ virus surface antigen ( $\mathrm{HBsAg}$ ) and subsequent management, Qiandongnan prefecture, Guizhou, China, 2010. Vaccin. 2013;31 Suppl 9:J62-5.

2. Lao TT, Sahota DS, Law LW, Cheng YK, Leung TY. Age-specific prevalence of hepatitis B virus infection in young pregnant women, Hong Kong Special Administrative Region of China. Bull World Health Organ. 2014;92(11):782-9.

3. Sorrell MF, Belongia EA, Costa J, Gareen IF, Grem JL, Inadomi JM, Kern ER, McHugh JA, Petersen GM, Rein MF et al. National Institutes of Health consensus development conference statement: management of hepatitis B. Hepatol. 2009:49(5 Suppl):S4-S12.

4. Yu M, Jiang Q, Gu X, Ju L, Ji Y, Wu K, Jiang H. Correlation between vertical transmission of hepatitis $B$ virus and the expression of HBsAg in ovarian follicles and placenta. PLoS One. 2013:8(1):e54246.

5. Lin X, Guo Y, Zhou A, Zhang Y, Cao J, Yang M, Xiao F, Zhang B, Du Y. Immunoprophylaxis failure against vertical transmission of hepatitis $B$ virus in the Chinese population: a hospital-based study and a meta-analysis. Pediatr Infect Dis J. 2014;33(9):897-903.

6. Pastorek 2nd JG, Miller Jr JM, Summers PR. The effect of hepatitis B antigenemia on pregnancy outcome. Am J Obstet Gynecol. 1988; 158(3 Pt 1):486-9.

7. Yue YF, Zhang SL, Li GL. The effect of HBsAg antigenemia on pregnancy. J of Xi'an Med Univ. 1995;7(2):136-8.

8. Wong $S$, Chan $L Y, Y u$ V, Ho L. Hepatitis B carrier and perinatal outcome in singleton pregnancy. Am J Perinatol. 1999;16(9):485-8.

9. Tse KY, Ho LF, Lao T. The impact of maternal HBsAg carrier status on pregnancy outcomes: a case-control study. J Hepatol. 2005:43(5):771-5.

10. Saleh-Gargari S, Hantoushzadeh S, Zendehdel N, Jamal A, Aghdam H. The Association of Maternal HBsAg Carrier Status and Perinatal Outcome. Hepat Mon. 2009;9(3):180-4.

11. Safir A, Levy A, Sikuler E, Sheiner E. Maternal hepatitis B virus or hepatitis $C$ virus carrier status as an independent risk factor for adverse perinatal outcome. Liver Int. 2010;30(5):765-70.

12. Elefsiniotis I, Tsoumakas K, Vezali E, Glynou I, Drakoulis N, Saroglou G. Spontaneous preterm birth in women with chronic hepatitis B virus infection. Int J Gynaecol Obstet. 2010;110(3):241-4

13. Connell LE, Salihu HM, Salemi JL, August EM, Weldeselasse H, Mbah AK. Maternal hepatitis B and hepatitis C carrier status and perinatal outcomes. Liver Int. 2011;31(8):1163-70.
14. Reddick KL, Jhaveri R, Gandhi M, James AH, Swamy GK. Pregnancy outcomes associated with viral hepatitis. J Viral Hepat. 2011;18(7):e394-8.

15. Sirilert S, Traisrisilp K, Sirivatanapa P, Tongsong T. Pregnancy outcomes among chronic carriers of hepatitis B virus. Int J Gynaecol Obstet. 2014; 126(2):106-10.

16. Shen Y, Zhang J, Cai H, Shao JG, Zhang YY, Liu YM, Qin G, Qin Y. Identifying patients with chronic hepatitis $B$ at high risk of type 2 diabetes mellitus: a cross-sectional study with pair-matched controls. BMC Gastroenterol. 2015;15:32.

17. Zhu L, Zhang R, Zhang S, Shi W, Yan W, Wang X, Lyu Q, Liu L, Zhou Q, Qiu $Q$ et al. Chinese neonatal birth weight curve for different gestational age. Zhonghua er ke za zhi Chinese J Pediatr. 2015;53(2):97-103.

18. Xu B, Jarvelin MR, Xu X, Wang Z, Qin H, Rimpela A. Maternal menstrual history and small-for-gestational-age births in a population-based Chinese birth cohort. Early Hum Dev. 1997;49(3):183-92.

19. Hellerstein S, Feldman S, Duan T. China's $50 \%$ caesarean delivery rate: is it too high? BJOG. 2015;122(2):160-4.

20. el-Sayed Zaki M, Goda H. Relevance of parvovirus B19, herpes simplex virus 2 , and cytomegalovirus virologic markers in maternal serum for diagnosis of unexplained recurrent abortions. Arch Pathol Lab Med. 2007;131(6):956-60.

21. Konstantinidou A, Anninos H, Spanakis N, Kotsiakis X, Syridou G, Tsakris A, et al. Transplacental infection of Coxsackievirus B3 pathological findings in the fetus. J Med Virol. 2007;79(6):754-7.

22. Sauerbrei A, Wutzler P. Varicella-Zoster Virus Infections During Pregnancy: Epidemiology, Clinical Symptoms, Diagnosis, Prevention and Therapy. Curr Pediatr Rev. 2005:1:205-16.

23. Siegel M, Fuerst HT, Peress NS. Comparative fetal mortality in maternal virus diseases. A prospective study on rubella, measles, mumps, chicken pox and hepatitis. N Engl J Med. 1966;274(14):768-71.

24. McMahon BJ. The natural history of chronic hepatitis B virus infection. Hepatol. 2009:49(5 Suppl):S45-55.

25. Andreani T. HBV-carriers: When is monitoring and surveillance sufficient? (point of view). Clin Res Hepatol Gastroenterol. 2011;35(12):813-8.

26. Ch'ng CL, Morgan M, Hainsworth I, Kingham JG. Prospective study of liver dysfunction in pregnancy in Southwest Wales. Gut. 2002:51(6):876-80.

27. Regan L, Braude PR, Trembath PL. Influence of past reproductive performance on risk of spontaneous abortion. BMJ. 1989:299(6698):541-5.

28. Bick RL, Madden J, Heller KB, Toofanian A. Recurrent miscarriage: causes, evaluation, and treatment. Medscape Womens Health. 1998;3(3):2

29. Practice Committee of the American Society for Reproductive M. Evaluation and treatment of recurrent pregnancy loss: a committee opinion. Fertil Steril. 2012;98(5):1103-11.

30. Thorp Jr JM, Hartmann KE, Shadigian E. Long-term physical and psychological health consequences of induced abortion: review of the evidence. Obstet Gynecol Surv. 2003;58(1):67-79.

\section{Submit your next manuscript to BioMed Central and we will help you at every step:}

- We accept pre-submission inquiries

- Our selector tool helps you to find the most relevant journal

- We provide round the clock customer support

- Convenient online submission

- Thorough peer review

- Inclusion in PubMed and all major indexing services

- Maximum visibility for your research

Submit your manuscript at www.biomedcentral.com/submit
) Biomed Central 